\title{
Co-invading ectomycorrhizal fungal succession in pine-invaded mountain grasslands
}

\author{
Tomás Milani ${ }^{1}$, Jason Hoeksema ${ }^{2}$, Esteban Jobbágy ${ }^{1}$, J Alejandro Rojas ${ }^{3}$, Rytas Vilgalys ${ }^{4}$, \\ and François Teste ${ }^{5}$ \\ ${ }^{1}$ Instituto de Matematica Aplicada San Luis \\ ${ }^{2}$ University of Mississippi \\ ${ }^{3}$ University of Arkansas Fayetteville \\ ${ }^{4}$ Duke University \\ ${ }^{5}$ The University of Western Australia
}

August 9, 2021

\begin{abstract}
Pines (Pinus spp.) rely on co-introduced ectomycorrhizal (EM) fungi to invade native ecosystems in the Southern Hemisphere. Although co-invasive EM fungal communities are expected to be poor in species, long-term successional trajectories and the persistence of dispersal limitations are not well understood. We sampled the roots and surrounding soil of Pinus elliottii and P. taeda trees invading mountain grasslands of Argentina. We also sampled the EM fungal spore bank in grassland soil near $(\sim 150 \mathrm{~m})$ and far $(\sim 850 \mathrm{~m})$ from original pine plantations. We found an impressive total of 47 different co-invasive EM fungal OTUs. Differential dispersal capacities among EM fungi were detected in the spore bank of grassland soil, but not under mature invading pines. After thirty years of invasion, the age but not the degree of spatial isolation of pine individuals affected the EM fungal composition. We showed that invading pines can host a highly diverse EM fungal community and although dispersal limitations can be important during the colonization of non-invaded sites, they can be overcome in the life-span of pines, allowing EM succession to continue. These results enhance our understanding of the spatial structure and dispersal dynamics of EM fungi during pine invasions.
\end{abstract}

\section{Hosted file}

Milani_etal_CombinedManuscript.docx available at https://authorea.com/users/429838/articles/ 533453-co-invading-ectomycorrhizal-fungal-succession-in-pine-invaded-mountain-grasslands 